\title{
Ultrasonographic analysis of senile cataractous lens of dogs and its correlation to phacoemulsification
}

\author{
[Análise ultrassonográfica da lente cataratogênica senil de cães e sua correlação com \\ parâmetros de facoemulsificação] \\ B.C. Martins ${ }^{1,2}$, A.P. Ribeiro ${ }^{1}$, J.P.D. Ortiz ${ }^{1}$, C.B.S. Lisbão ${ }^{1}$, A.L.G. Souza ${ }^{1}$, \\ D. Brooks ${ }^{2}$, J.L. Laus ${ }^{1 *}$ \\ ${ }^{1}$ Faculdade de Ciências Agrárias e Veterinárias - UNESP \\ Via de Acesso Prof. Paulo Donato Castellane, s/n \\ 14884-900 - Jaboticabal, SP \\ ${ }^{2}$ Department of Small and Large Animal Clinical Sciences \\ University of Florida - Gainesville, FL - EUA
}

\begin{abstract}
This study aimed to evaluate the effectiveness of a computer-assisted ultrasound analysis of senile dogs cataractous lens and identify its correlation to phacoemulsification surgical parameters. Simultaneous A- and B- mode ultrasonic evaluation of the lens was performed on 15 dogs with cataract. A computer-assisted image analysis was used to objectively calculate the lens echogenicity. Following ultrasonographic examination the cataracts were removed by phacoemulsification and the ultrasonographic and phacoemulsification findings were compared to identify possible correlations. Lens echogenicity obtained by the computer-assisted ultrasonographic analysis correlated to the phacoemulsification time, such that the whiter the ultrasound image, the longer was the phacoemulsification time. The B-mode ultrasonography was helpful for the prediction of lens opacity location, but not predictive of lens hardness.
\end{abstract}

Keywords: dog, cataract, echogenicity, ultrasonography, phacoemulsification

\section{RESUMO}

Avaliou-se a eficácia da análise ultrassonográfica, assistida por computador, da lente cataratogênica senil de cães e identificou-se sua correlação com parâmetros da facoemulsificação. A avaliação ultrassonográfica da lente em modos A e B simultâneos foi realizada em 15 cães portadores de catarata. Procedeu-se à análise das imagens, assistida por computador. Posteriormente, os olhos selecionados foram submetidos à facoemulsificação. Os achados ultrassonográficos e a facoemulsificação foram comparados visando à identificação de possíveis correlações. A ecogenicidade obtida por meio da análise ultrassonográfica correlacionou-se diretamente com o tempo de facoemulsificação, de maneira que quanto mais branca a imagem ultrassonográfica, maior o tempo de facoemulsificação. A ultrassonografia em modo-B auxiliou na predição da localização das opacidades lenticulares, porém não auxiliou na predição da dureza da lente.

Palavras-chave: cão, catarata, ecogenicidade, ultrassonografia, facoemulsificação

\section{INTRODUCTION}

Cataracts are one of the most frequent intraocular diseases and the major cause of blindness in humans and dogs. Some types of cataracts are still a challenge for the ophthalmologist. Specifically in dogs, the senile cataract can be one of the most challenging (Brazitikos et al., 1999; Tabandeh et al., 2000). The success rate is higher when the surgery is performed in young dogs (up to 6 years old). Also, some authors reported more complications during surgery, and longer post-operative time in old dogs with mature cataracts (Özgencil, 2005).

Recebido em 10 de novembro de 2010

Aceito em 18 de maio de 2011

*Autor para correspondência (corresponding author)

E-mail: jllaus@fcav.unesp.br 
An accurate evaluation of the lens is obligatory before its removal in order to achieve the best postoperative result (Slatter, 2001). Therefore, the ocular ultrasonography should be imperative before cataract extraction and its importance has been well described and accepted (Krasnov et al., 2000; Brazitikos et al., 2003; Ermis et al., 2003). The evaluation of the lens through ultrasound has been reported by some authors (Soares et al., 1998; Martins et al., 2010b). The normal lens thickness of dogs has been determined, varying from 7.3 to $9.8 \mathrm{~mm}$ (Williams, 2004). Lens thickness was also determined in cataractous canine lenses (Williams, 2004; Martins et al., 2010a). The authors concluded that lenses affected with diabetic cataract had increased diameter, compared to those with mature cataract, and mature cataract had higher dimensions compared to immature cataracts.

The correlation between ultrasonographic features of the lens and phacoemulsification aspects has been studied in humans by Brazitikos et al. (1999). An A-scan echography was performed in 100 senile cataractous eyes prior to phacoemulsification. Capsulorrhexis performance showed increased risk of tearing in intumescent white cataract with cortex liquefaction and white cataract with fibrosed anterior capsule. In addition, the authors reported that the phacoemulsification technique was not as successful in patients with substantial voluminous hard nucleus. Some years later, Brazitikos et al. (2003) carried out another study correlating the A-scan ultrasonography of senile cataracts and phacoemulsification parameters in humans. In this study, the mean height of internal lens spikes observed during A-scan ultrasonography correlated negatively with phacoemulsification time and mean percent phacoemulsification power.

Considering the lack of data correlating the ultrasonography of the lens of dogs and phacoemulsification, the aim of this study was to evaluate the effectiveness of the computerassisted ultrasound analysis and ultrasonographic aspects of senile cataractous canine lenses in order to determine any correlation to phacoemulsification surgical parameters.

\section{MATERIAL AND METHODS}

The research was carried out in the Ophthalmology Unit of a Teaching Veterinary Hospital. The project was submitted to and approved by the Committee of Ethics and Animal Welfare of the Escola de Ciências Agrárias e Veterinárias, UNESP, Jaboticabal, SP (Protocol 007105-06). The study followed the guidelines from Association for Research in Vision and Ophthalmology (ARVO) National Institutes of Health Publications No 85-23, Revised 1985).

For the study, dogs affected with different stages of senile cataract were selected to undergo phacoemulsification. Routine clinical ophthalmic examination was performed including dazzle and menace tests, pupillary light reflex, Schirmer tear test (Schirmer tear test strips ${ }^{\circledR}$, Ophthalmos Ltda, São Paulo, Brazil), slit-lamp biomicroscopy (Slit Lamp SL-14®, Kowa Company Ltd, Torrance, USA), tonometry (TonoPen XL®, Medtronic, Jacksonville, USA (TonoPen XL®, Medtronic, Jacksonville, USA ), gonioscopy (Koeppe medium diagnostic lens 18 mm, Volk Optical Inc., Mentor, USA), fluorescein staining (Fluorescein strips ${ }^{\circledR}$, Ophthalmos Ltda, São Paulo, Brazil), indirect binocular ophthalmoscopy (Binocular indirect ophthalmoscope FOH-5®, Eyetec S.A, São Carlos, Brazil) and electroretinography (Electroretinography Epic 2000®, LKC, Gaithersburg, USA). Diabetic dogs were not included in the study.

A- and B-mode ultrasonography were simultaneously performed using a $10 \mathrm{mHz}$ ocular ultrasound scanner (Ultrascan A/B®, Alcon, Fort Worth, USA). Topical $0.5 \%$ proximetacaine (Anestalcon, Alcon do Brasil, São Paulo, Brazil) was used for corneal anesthesia and animals were positioned in sternal recumbency. The eyelids were manually held open and adequate contact between the probe and the ocular surface was obtained with sterile ultrasound gel. Simultaneous A and B modes were used for lens biometry, aiming for better visualization of corneal, anterior lens capsular, posterior lens capsular and retinal spikes. The probe was positioned axially on the cornea. Measurements of the axial globe length, anterior chamber depth, and lens and vitreous diameter were determined 
using the measurement facilities of the A/Bmode ultrasound scanner.

Ultrasonographic lens examination was performed by B-mode following the determination of globe measurements. The transpalpebral method was used with the transducer first positioned axially on the cornea and then redirected on the limbus to scan the entire globe. The lens of each eye was classified as having hyperechoic or hypoechoic areas. Areas of normal appearance were classified as being echolucent. Alterations in the posterior segment were also investigated prior to cataract extraction. All ultrasonographic examinations were performed by the same author.
A computer-assisted imaging technique was used to calculate and analyze the ultrasound lens opacities. After digitalization of the ultrasound images as TIFF file, public domain software (Image J., National Institutes of Health) was used. The software quantifies the echogenicity of the digital image obtained, so that the echogenicity of the lens can be measured (Soder et al., 2009). Each image pixel is graded in a gray scale ranging from 0 (black) to 255 (white) and the mean echogenicity of a region of interest (ROI) is provided (lens echogenic index). For the analysis, the lens was selected as the ROI (Fig. 1). Both elliptical and free-hand selections were used and compared, as well as different adjustment parameters for contrast and brightness.

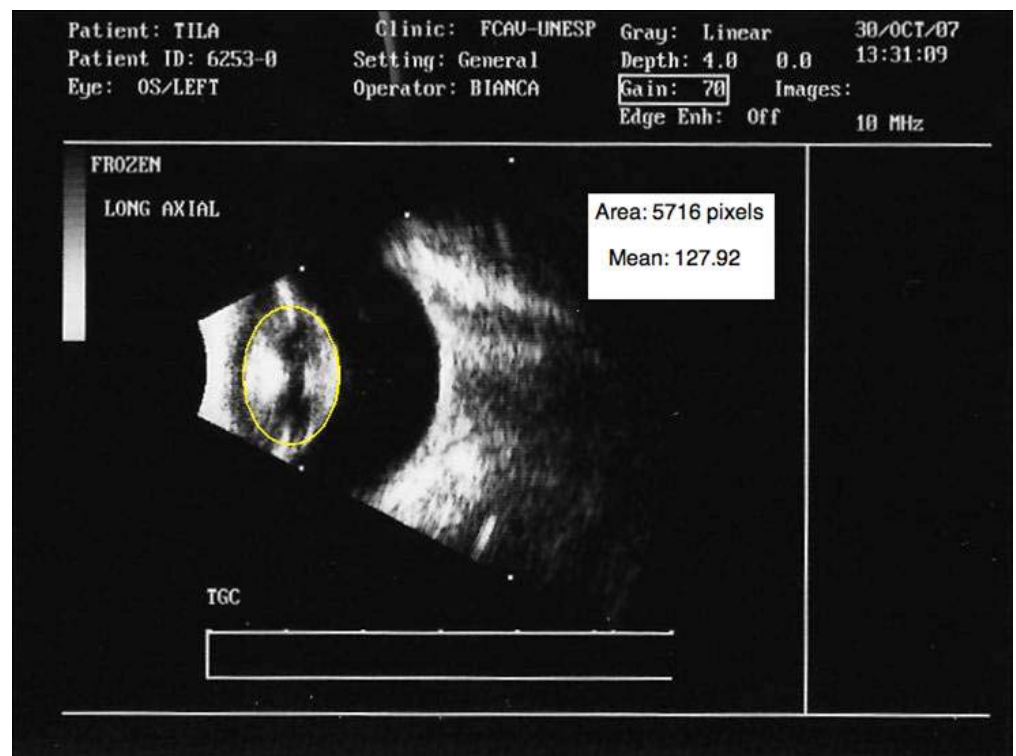

Figure 1. Dog. Ultrasonographic image showing the lens selected as a region of interest (yellow circle) for echogenicity analysis and echogenic index.

Selected eyes underwent phacoemulsification (one eye from each dog). Preoperatively, 1\% prednisolone (Predfort ${ }^{\circledR}$, Allergan, São Paulo, Brazil) and $0.3 \%$ tobramycin (Tobrex ${ }^{\circledR}$, Alcon do Brasil, Sao Paulo, Brazil) were given topically four times a day during seven days, along with $1 \%$ atropine (Sulfato de atropina $1 \% \AA$, Allergan, São Paulo, Brazil) 12 hours and 30 minutes before surgery. Also systemic flunixin meglumine (Banamine ${ }^{\circledR}$, Schering Plough, São Paulo, Brazil) (1mg/kg IM) was administered 30 minutes before surgery.
Animals received meperidine (Dolantina ${ }^{\circledR}$, Aventis Pharma, São Paulo, Brazil) (5mg/kg IV) and diazepam (Diazepamil ${ }^{\circledR}$, Hipolabor, Sabara, Brazil) $\quad(0.3 \mathrm{mg} / \mathrm{kg}$ IV) as premedication. Anesthesia induction was achieved by intravenous injection of propofol (Profolen ${ }^{\circledR}$, Blausiegel, Cotia, Brazil) (5mg/kg). General anesthesia was maintained with isofluorane (Isoforine ${ }^{\circledR}$, Cristália, Itapira, Brazil) in a semi open circuit. Surgical procedures were performed with the aid of an operating microscope (MCM3101, DFV, Valença, Brazil). 
All surgical procedures were performed by the same author. A clear corneal incision was made using a 15 degree knife (Slit knife 15 degrees ${ }^{\circledR}$, Alcon do Brasil, São Paulo, Brazil) at 11-o’clock position. An air bubble was introduced followed by anterior lens staining (Trypan blue ${ }^{\circledR}$ Ophthalmos, São Paulo, Brazil) which was rinsed with balanced saline solution (Balanced Saline Solution ${ }^{\circledR}$ (BSS), Alcon do Brasil, São Paulo, Brazil). Sodium chondroitin sulfate (4\%) plus $3 \%$ sodium hyaluronate as well as $1 \%$ sodium hyaluronate (Duovisc ${ }^{\circledR}$, Alcon do Brasil, São Paulo, Brazil) were used as viscoelastic material in soft-shell technique. Corneal incision was widened with a 3.2 slit knife (Surgical knife 3.2mm ${ }^{\circledR}$, Alcon do Brasil, São Paulo, Brazil). Capsulorrhexis was performed with an Utrata forceps followed by hydrodissection to separate the lens cortex from its capsule. All surgeries were performed with the same phacoemulsification machine (Universal II Alcon, Fort Worth, USA) using $500 \mathrm{ml}$ BSS with $1 \mathrm{ml}$ epinephrine as irrigating solution. Nucleus and cortex were emulsified and aspirated through the divide-and-conquer technique. The remaining cortex and viscoelastic material were aspirated with an irrigation and aspiration device. Corneal incision was closed with simple interrupted sutures of 9-0 nylon (Mononylon 9-0®, Ethicon, Cornelia, USA). Immediately at the end of surgery, $0.3 \mathrm{~mL}$ subconjunctival betamethasone was administered (Diprospan ${ }^{\circledR}$ - Schering Plough, São Paulo, Brazil).

Throughout the surgical procedures, different lens areas (axial and equatorial anterior cortex, nucleus and axial and equatorial posterior cortex) were subjectively classified regarding their cataract extent as mild $(+)$, moderate $(++)$ or severe $(+++)$. Regarding their hardness, different lens areas were subjectively classified as soft $(+)$, moderately hard $(++)$ or hard $(+++)$. At the end of the procedures, phacoemulsification time and surgical events were recorded and a correlation with previous ultrasonographic exams was investigated.

Following surgery, $0.3 \%$ tobramycin and 1\% prednisolone were given topically every 4 hours, in addition to $1 \%$ brinzolamide (Azopt ${ }^{\circledR}$, Alcon do Brasil, São Paulo, Brazil) every 6 hours, during 7 days. These medications were gradually withdrawn one week after surgery. Topical $1 \%$ atropine was instilled every 12 hours during 2 days. Firocoxib (Previcox®, Merial, Campinas, Brazil) (5mg/kg PO) once a day and cephalexin (Cefalexina ${ }^{\circledR}$, EMS, Hortolândia, Brazil) (25mg/kg) twice a day were used as systemic anti-inflammatory and antibiotic therapies, respectively, for 15 days. All animals wore an Elizabethan collar for protection. Animals were rechecked at days 7, 14, 21, 30, 45 and 60 after surgery, observing clinical events, intraocular pressure and visual perception.

The correlation among the variables: lens length, opacity location, axial globe length, phacoemulsification time, cataract type and lens echogenic index was obtained using Pearson correlation coefficient. PASW Statistics 18 (IBM SPSS inc. 2009) software was used to calculate the values and significance of correlation among the variables mentioned above. The variables were categorized by distribution and coherence according to biological significance. A positive correlation was verified when $\mathrm{P} \leq 0.05$.

\section{RESULTS}

A total of 28 eyes of 15 dogs were evaluated. All patients were between 8 and 14 years of age. Two dogs had unilateral cataracts. Eyes presenting lens luxation or subluxation, vitreous hemorrhage and persistent hyaloid artery detected at clinical or ultrasonographic examination were not selected for surgical procedures. Eyes with uveitis were treated prior to lens surgery. Therefore, 15 eyes of 15 dogs were selected for the study (six right eyes, nine left eyes).

During ultrasonographic examination cataracts were found to be anterior cortical, posterior cortical, nuclear and posterior capsular in six eyes (40\%) (Fig. 2 and 3), anterior cortical, posterior cortical and nuclear in five eyes (33.3\%), anterior cortical and posterior cortical in two eyes (13.3\%) and anterior cortical, nuclear and posterior capsular in two eyes (13.3\%) (Table 1). 


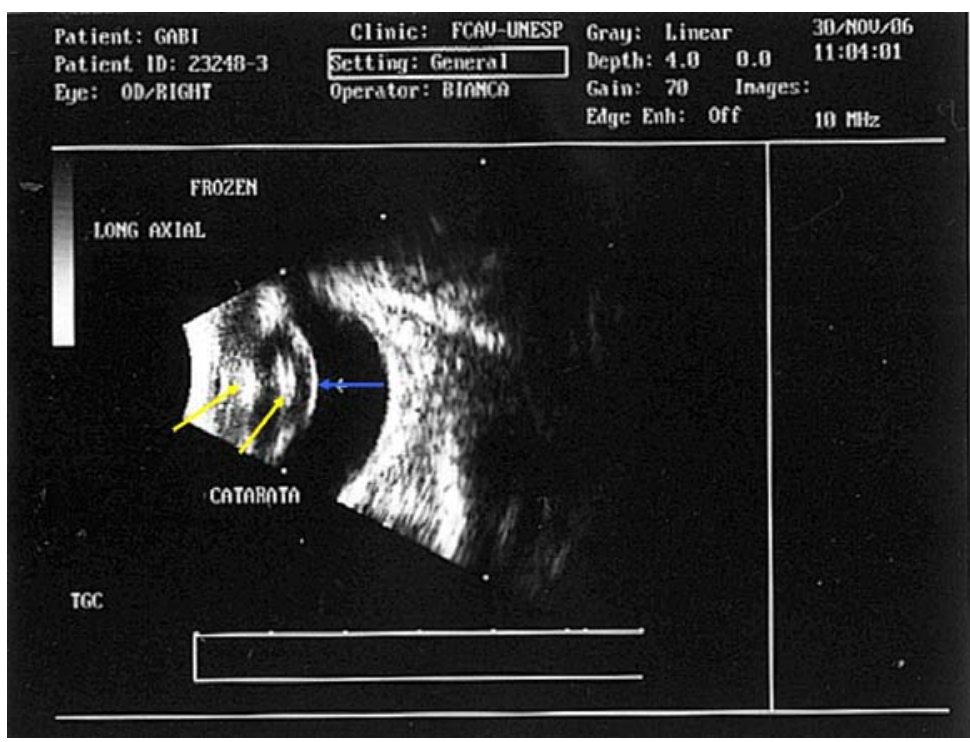

Figure 2. Ultrasonographic image (horizontal, mode B) of the right eye of a dog with immature cataract. Hyperechoic anterior and posterior cortex (axial), nucleus (yellow arrows), and posterior lens capsule (blue arrow).

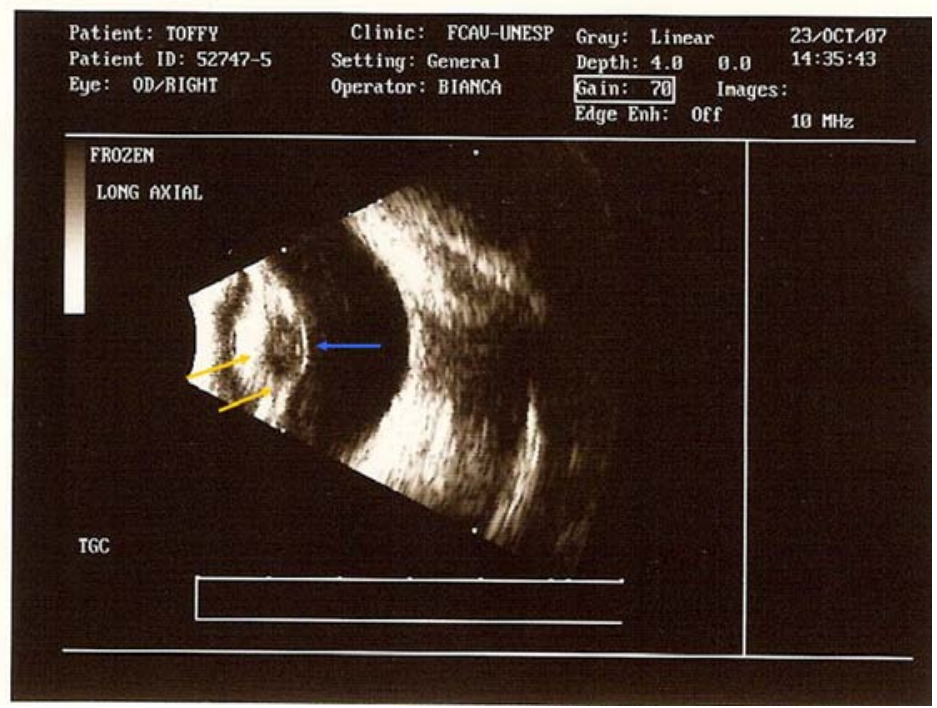

Figure 3. Ulrasonographic image (horizontal, mode B) of the right eye of a dog with a mature cataract. Hyperechoic anterior cortex (axial and equatorial), nucleus and posterior cortex (equatorial) (yellow arrows) are present. Hyperechoic posterior lens capsule (blue arrow).

Simultaneous A and B mode ultrasonography was efficient for the observation of cornea, anterior and posterior lens capsule, and retinachoroid-sclera spikes (Fig. 4). Axial globe length obtained by simultaneous A/B mode ultrasonography for selected eyes varied from 17.10 to $21.01 \mathrm{~mm}$ (mean \pm SD: $19.15 \pm 1.21 \mathrm{~mm}$ ). Anterior chamber depth varied from 1.40 to $3.27 \mathrm{~mm}$ (mean \pm SD: $2.35 \pm 0.51 \mathrm{~mm}$ ). Lens thickness measured from 5.84 to $10.83 \mathrm{~mm}$ (mean \pm SD: $7.87 \pm 1.5 \mathrm{~mm}$ ) and vitreous chamber anterior-posterior measurement obtained varied from 7.17 to $10.83 \mathrm{~mm}$ (mean \pm SD: $8.94 \pm 1.09 \mathrm{~mm})$. When individually compared to the phacoemulsification time and findings (location of opacities and lens hardness), the biometry of lens size, anterior chamber depth and axial diameter do not offer consistent data that could help the prediction of the surgery. 
Ultrasonographic analysis...

Table 1. Ultrasonographic findings and lens echogenic index (LEI) of right (D) and left (S) eyes of dogs with senile cataract selected for phacoemulsification.

\begin{tabular}{|c|c|c|c|}
\hline Animal & Eye & LEI & Ultrasonographic finding \\
\hline 1 & $\mathrm{D}$ & 107.95 & Hyperechoic AC (axial and equatorial). Hypoechoic PC (axial and equatorial). \\
\hline 2 & $\mathrm{D}$ & 142.69 & $\begin{array}{l}\text { Hyperechoic AC (axial and equatorial), } \mathrm{N} \text { and PC (equatorial). Hypoechoic PC } \\
\text { (axial). Focal hypoechoic echoes in vitreous. }\end{array}$ \\
\hline 3 & S & 85.68 & Hyperechoic AC (axial), N and PC (equatorial). Hypoechoic AC (equatorial). \\
\hline 4 & $\mathrm{D}$ & 108.69 & Hyperechoic AC (axial), N and PC (axial). Hyperechoic PLC. \\
\hline 5 & S & 128.07 & $\begin{array}{l}\text { Hyperechoic AC (axial and equatorial), N and PC (equatorial). Hypoechoic PC } \\
\text { (axial). }\end{array}$ \\
\hline 6 & S & 97.73 & $\begin{array}{l}\text { Hyperechoic PC (axial) and N. Hypoechoic AC (equatorial) and PC (axial). } \\
\text { Hyperechoic PLC. }\end{array}$ \\
\hline 7 & $\mathrm{D}$ & 92.38 & $\begin{array}{l}\text { Hyperechoic AC (axial), N, PC (axial) and PLC. Hypoechoic AC and PC } \\
\text { (equatorial). }\end{array}$ \\
\hline 8 & $\mathrm{~S}$ & 137.67 & $\begin{array}{l}\text { Hyperechoic AC and PC (axial). Hypoechoic AC (equatorial). Diffuse } \\
\text { hypoechoic echoes in vitreous. }\end{array}$ \\
\hline 9 & S & 122.26 & Hyperechoic AC (axial and equatorial) and N. Hyperechoic PLC. \\
\hline 10 & $\mathrm{D}$ & 128.04 & $\begin{array}{l}\text { Hyperechoic AC (axial and equatorial) and N. Hypoechoic PC (axial). } \\
\text { Hyperechoic PLC. }\end{array}$ \\
\hline 11 & S & 127.92 & Hyperechoic AC, PC (axial) and N. Hypoechoic AC and PC (equatorial). \\
\hline 12 & $\mathrm{D}$ & 114.32 & Hyperechoic AC (axial and equatorial), $\mathrm{N}$ and PC (axial). \\
\hline 13 & $\mathrm{~S}$ & 111.49 & Hyperechoic AC, PC (axial) and N. Hyperechoic PLC. \\
\hline 14 & S & 136.50 & $\begin{array}{l}\text { Hyperechoic AC (axial and equatorial), N and PC (equatorial). Hypoechoic PC } \\
\text { (axial). Hyperechoic PLC. Linear opacities at posterior segment. }\end{array}$ \\
\hline 15 & $\mathrm{~S}$ & 113.45 & Hyperechoic AC (axial and equatorial) and N. Hyperechoic PLC. \\
\hline
\end{tabular}

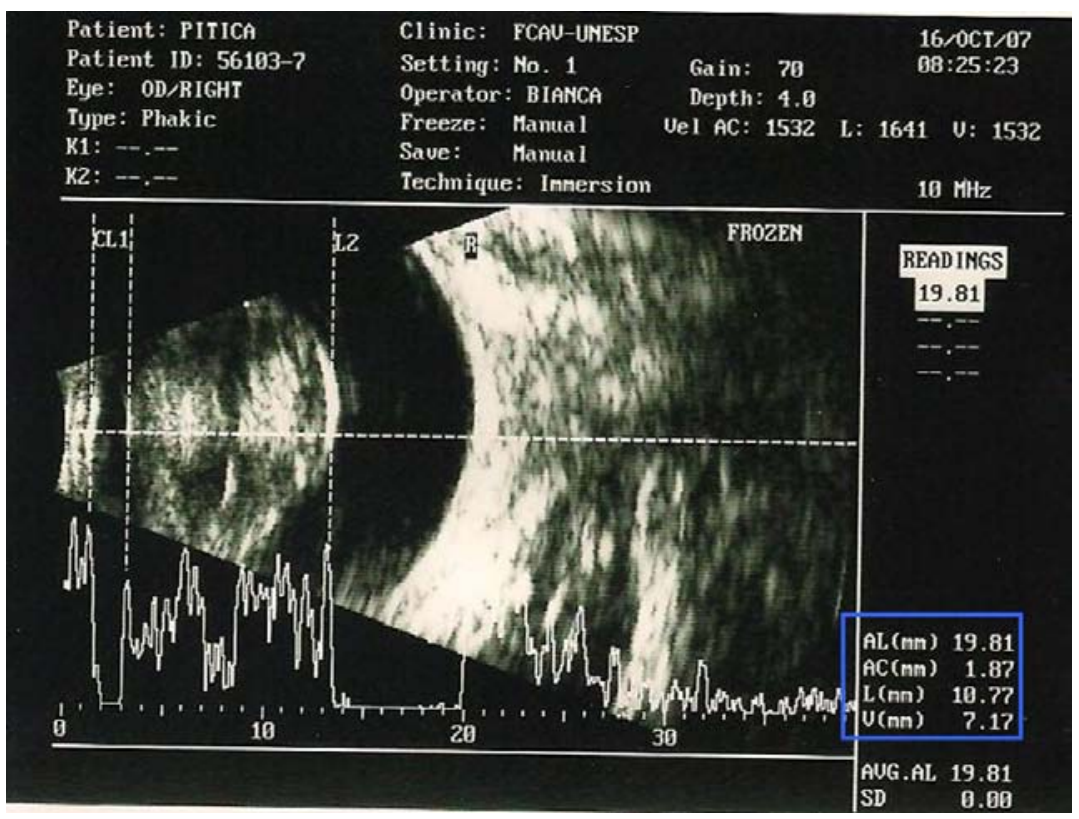

Figure 4. Ultrasonographic image (simultaneous mode A and B) of right eye of a dog with mature cataract. Biometry (blue box) shows the measures related to anterior length, anterior chamber, lens and vitreous.

The computer-assisted image analysis of the digital ultrasound images revealed that the lens echogenicity ranged from 92.38 to 142.69 , where $0=$ black and $255=$ white. The results are shown on Table 1. No statistical differences were found between the echogenicity values obtained by elliptical or free-hand selection, as well as for different adjustment parameters for contrast and brightness. 
All surgeries were carried out with no complications except for one (animal number 3), that had the posterior capsule ruptured during surgery and resulted in vitreous presentation. Phacoemulsification time varied from 3.9 to 12.7min (mean \pm SD: 7.89 $\pm 3.33 \mathrm{~min}$ ).

In the majority of the animals, different cataract densities were observed in the same lens, and hard and soft consistencies were frequently presented in different sites of the same lens. Phacoemulsification findings are presented in Table 2 and those regarding lens hardness are shown on Table 3.

Ultrasonographic findings of lens morphology were individually compared to the phacoemulsification findings and it was noted that the simultaneous $\mathrm{A} / \mathrm{B}$ mode ultrasound was helpful for the prediction of the lens opacities locations. It was observed that hyperechoic areas corresponded to the areas with major opacities observed during surgical procedures in seven eyes $(46.7 \%)$ thus a positive association was present between both aspects. Six eyes (40\%) had positive association between ultrasonographic and phacoemulsification findings in some, but not all of the lens areas. In three eyes (13.3\%) only a few areas of the lens showed a positive association between ultrasonographic and phacoemulsification findings.

In a similar way, lens hardness determined during phacoemulsification procedures was individually compared to ultrasonographic findings and it was found that the simultaneous A/B ultrasound was not helpful for the prediction of lens hardness. A positive association was observed in only four eyes (26.7\%). Eight eyes (53.3\%) exhibited some association between lens hardness and ultrasonographic opacities and in three eyes (20\%) no association was observed between those two parameters.

It was found that the whiter the ultrasound image of the lens, the longer the phacoemulsification time. This association was confirmed by the statistical analysis, which revealed a positive correlation between phacoemulsification time and lens echogenic index $(\mathrm{P}=0.05)$. Statistics revealed no other correlation among variables (lens length, opacity location, axial globe length, phacoemulsification time, cataract type and lens echogenic index).

Table 2. Phacoemulsification results in right (D) and left (S) eyes of dogs with senile cataract

\begin{tabular}{|c|c|c|c|}
\hline Animal & Eye & $\begin{array}{l}\text { Phaco time } \\
\text { (min) }\end{array}$ & Surgical finding \\
\hline 1 & $\mathrm{D}$ & 9.7 & $\begin{array}{l}\text { Hard equator through entire lens. Posterior dense plaque adhered to } \\
\text { posterior capsule. Focal opacities at posterior lens capsule. }\end{array}$ \\
\hline 2 & $\mathrm{D}$ & 12.7 & Soft nucleus. Hard posterior cortex adhered to posterior capsule. \\
\hline 3 & $\mathrm{~S}$ & 7.9 & $\begin{array}{l}\text { Soft nucleus. Equator mildly affected. Posterior lens capsule rupture } \\
\text { followed by vitreous presentation. }\end{array}$ \\
\hline 4 & $\mathrm{D}$ & 6.4 & Moderate hard nucleus. Soft equator mildly affected. \\
\hline 5 & $\mathrm{~S}$ & 12.5 & $\begin{array}{l}\text { Hard equator, anterior cortex moderately hard. Vacuoles with liquefied } \\
\text { lenticular material inside the lens. }\end{array}$ \\
\hline 6 & $\mathrm{~S}$ & 9.5 & Hard anterior cortex and lens. Soft equator with mild opacifications. \\
\hline 7 & $\mathrm{D}$ & 4.7 & $\begin{array}{l}\text { Soft consistency in all lens areas. Equator mildly affected. Vacuoles with } \\
\text { liquefied lenticular material inside the lens. }\end{array}$ \\
\hline 8 & $\mathrm{~S}$ & 12.3 & $\begin{array}{l}\text { Hard anterior cortex (axial). Anterior lens capsule adhered to cortex in } \\
\text { axial position. Soft equator and vacuoles with liquefied lenticular material. }\end{array}$ \\
\hline 9 & $\mathrm{~S}$ & 6.4 & Hard anterior cortex (axial) and nucleus. Soft equator in all lens areas. \\
\hline 10 & $\mathrm{D}$ & 12.0 & Hard nucleus. Soft equator in all lens areas. \\
\hline 11 & $\mathrm{~S}$ & 7.3 & Hard anterior cortex and nucleus. \\
\hline 12 & $\mathrm{D}$ & 3.9 & $\begin{array}{l}\text { Soft consistency in all lens areas. Equator mildly affected. Lenticular } \\
\text { sutures separated. }\end{array}$ \\
\hline 13 & $\mathrm{~S}$ & 4.5 & Soft consistency in all lens areas. Equator mildly affected. \\
\hline 14 & $\mathrm{~S}$ & 4.7 & Soft consistency in all lens areas, mainly posterior cortex and nucleus. \\
\hline 15 & $S$ & 4.0 & $\begin{array}{l}\text { Soft anterior and posterior cortex. Nucleus moderately hard. Vacuoles } \\
\text { with liquefied lenticular material inside the lens. }\end{array}$ \\
\hline
\end{tabular}


Ultrasonographic analysis...

Table 3. Lens consistency observed during phacoemulsification in different lens areas

\begin{tabular}{|c|c|c|c|c|c|}
\hline Animal & AC axial & AC equatorial & Nucleus & PC axial & PC equatorial \\
\hline 1 & ++ & +++ & ++ & ++ & +++ \\
\hline 2 & ++ & ++ & + & +++ & +++ \\
\hline 3 & ++ & + & + & + & + \\
\hline 4 & ++ & + & ++ & ++ & + \\
\hline 5 & ++ & +++ & + & + & +++ \\
\hline 6 & +++ & + & +++ & ++ & + \\
\hline 7 & + & + & + & + & + \\
\hline 8 & +++ & + & + & +++ & + \\
\hline 9 & ++ & + & ++ & + & + \\
\hline 10 & ++ & + & ++ & ++ & + \\
\hline 11 & +++ & + & +++ & ++ & + \\
\hline 12 & ++ & + & + & + & + \\
\hline 13 & ++ & + & + & + & + \\
\hline 14 & ++ & + & + & + & + \\
\hline 15 & + & + & ++ & + & + \\
\hline
\end{tabular}

AC=anterior cortex; $\mathrm{PC}=$ posterior cortex; $+=$ soft; $++=$ moderately hard; $+++=$ hard

\section{DISCUSSION AND CONCLUSION}

In this study, both A-mode and B-mode ultrasonography were used simultaneously as suggested by Boroffka et al. (2006). However, the biometry of lens size, anterior chamber depth and axial diameter did not offer consistent data regarding the surgical aspects of lens during phacoemulsification.

Mean phacoemulsification time was 7.89 minutes. Özgencil (2005) reported a time of 5.30 minutes for mature cataracts. In the present study the use of less phaco time was obtained in animal 12 (3.9 minutes) despite its large lens size $(10.83 \mathrm{~mm})$. It is believed that the low use of the phaco function in this case was due to the soft consistency of the lens.

In most cases a hyperechoic area observed during ultrasonographic examination corresponded to an area of severe cataract extent observed during surgery, thus making the surgeries more predictive. These areas were not necessarily physically hard to fragment with the phaco needle, and in some cases the hyperechoic area was found to be soft during surgery. It is known that lens hardness may be influenced by alterations in the nature and concentration of proteins as well as lens fiber compaction and other biochemical changes. Since the hardness is directly associated to the lens molecular changes, the authors postulate that the echogenicity is not a reflex of the lens content or density and that might explain the absence of correlation between echogenicity and physical hardness.
The computer-assisted image analysis was found to be an accessible as well as useful and easy-to-use tool to evaluate the echogenicity of ultrasound images. The use of different adjustment parameters (contrast and brightness) and ROI selection methods (elliptical and free-hand) did not significantly change the obtained echogenicity values. The statistical analysis revealed a positive correlation between the lens echogenic index and phaco time, such that the whiter the lens ultrasound image, the longer the phacoemulsification time. Moreover, this method reduces examiner subjectivity and may be used to predict the phacoemulsification time.

Simultaneous A-mode and B-mode ultrasonography is able to determine the echogenic spikes of the cornea, anterior lens capsule, posterior lens capsule and retina necessary for the measurement of intraocular structures. The lens echogenicity correlates to the phacoemulsification time, such that the whiter the lens ultrasound image, the longer the phacoemulsification time. In that way, the computer-assisted image analysis of lens echogenicity may be useful in the prediction of the phacoemulsification time. The B-mode ultrasonography is helpful for clinically predicting opacified lens areas, but is not able to provide information regarding lens hardness. The biometry of lens size, anterior chamber depth and axial diameter does not offer consistent data that could help the prediction of surgical parameters. 


\section{ACKNOWLEDGEMENTS}

This study was supported by FAPESP (Grant 05/59086-5) and CAPES (Scholarship).

\section{REFERENCES}

BOROFFKA, A.E.B.; VOORHOUT, G.; VERBRUGGEN, A.M. et al. Intraobserver and interobserver repeatability of ocular biometric measurements obtained by means of B-mode ultrasonography in dogs. Am. J. Vet. Res., v.67, p.1743-1749, 2006.

BRAZITIKOS, P.D.; ANDROUDI, S.; PAPADOPOULOS, N.T. et al. A-scan quantitative echography of senile cataracts and correlation with phacoemulsification parameters. Curr. Eye Res., v.27, p.175-181, 2003.

BRAZITIKOS, P.D.; TSINOPOULOS, I.T.; PAPADOPOULOS N.T. et al. Ultrasonographic classification and phacoemulsification of white senile cataracts. Ophthalmology, v.106, p.21732178, 1999.

ERMIS, S.S.; ÔZTURK, F.; INAN, Û.Û. Comparing the efficacy and safety of phacoemulsification in white mature and other types of senile cataracts. Br. J. Ophthalmol., v.87, p.1356-1359, 2003.

KRASNOV, M.M.; MAKAROV, I.A.; IUSSEF, S.N. Densitometric analysis of crystalline lens nucleus in the choice of strategy of surgical treatment of cataracts. Vestnik Oftalmol., v.116, p.6-8, 2000.

MARTINS, B.C.; LIMA, F.S.; LAUS, J.L. Simultaneous mode A and mode B echobiometry of senile cataractous eyes in dogs. Arq. Bras. Med. Vet. Zootec., v.62, p.42-46, 2010a.
MARTINS, B.C.; RODRIGUES JUNIOR, E.F.; SOUZA, A.L.G. et al. A and B mode ultrasonography in preoperative evaluation of lens and posterior segment of dogs' eyes with cataract. Pesq. Vet. Bras., v.30, p.121-126, 2010b.

ÖZGENCIL, F.E. The results of phacofragmentation and aspiration surgery for cataract extraction in dogs. Turk. J. Vet. An. Sci., v.29, p.165-173, 2005.

SLATTER, D. Lens. In: Fundamentals of veterinary ophthalmology. Philadelphia: W.B. Saunders, 2001. p.381-410.

SOARES, A.M.B.; LAUS, J.L.; SIQUEIRA, Y.H. et al. Ultrassonografia bidimensional em tempo real do bulbo ocular de cães (Canis familiaris, LINNAEUS, 1758) com opacificação de meios transparentes. Emprego do transdutor mecânico setorial de 7,5MHz com almofada de recuo. Cienc. Rural, v.28, p.591-599, 1998.

SODER, R.B.; BALDISSEROTTO, M.; SILVA, V.D. Computer-assisted ultrasound analysis of liver echogenicity in obese and normal-weight children. Am. J. Roentgenol., v.192, p.w201-w205, 2009.

TABANDEH, H.; WILKINS, M.; THOMPSON, G. et. al. Hardness and ultrasonic characteristics of the human crystalline lens. J. Cataract Refrac. Surg., v.26, p.838-841, 2000.

WILLIAMS, D.L. Lens morphometry determined by B-mode ultrasonography of the normal and cataractous canine lens. Vet. Ophthalmol., v.7, p.91-95, 2004. 